\title{
El Pensamiento Crítico desde la Perspectiva de los Docentes Universitarios
}

\author{
Critical Thinking from the Perspective of University Teachers
}

\author{
María José Bezanilla Albisua ${ }^{a}$, Manuel Poblete Ruiz, Donna Fernández Nogueira ${ }^{c}$, \\ Sonia Arranz Turnes ${ }^{d}$, Lucía Campo Carrasco ${ }^{e}$ \\ ${ }^{a}$ Universidad de Deusto. \\ Correo electrónico: marijose.bezanilla@deusto.es \\ ${ }^{\mathrm{b}}$ Universidad de Deusto. \\ Correo electrónico: manuel.poblete@deusto.es. \\ ${ }^{\mathrm{c}}$ Universidad de Deusto. \\ Correo electrónico: donna.fernandez@deusto.es. \\ ${ }^{\mathrm{d}}$ Universidad de Deusto. \\ Correo electrónico: sonia.arranz@deusto.es. \\ ${ }^{\mathrm{e}}$ Colegio Monte Tabor-Schoensttat. \\ Correo electrónico: 1c.luciacampo@gmail.com.
}

\begin{abstract}
RESUMEN
Gracias al desarrollo del aprendizaje basado en competencias, se ha producido un gran interés por el pensamiento crítico en la educación superior. La empleabilidad, por otra parte, ha influido poderosamente en su protagonismo como competencia imprescindible en el desarrollo profesional en un entorno innovador. Diversos autores han estudiado el concepto de pensamiento crítico y los procesos implicados en su desarrollo y formación. El presente artículo analiza qué entienden los docentes universitarios por pensamiento crítico y la importancia que conceden al mismo. Es una investigación mixta cuantitativa/cualitativa, con 230 docentes universitarios, que desvela interesantes resultados, como que la mayoría lo vinculan a procesos de análisis y razonamiento, algunos al cuestionamiento, evaluación y toma de decisiones y muy pocos lo entienden como acción y compromiso, siendo para todos un aspecto muy importante de la formación universitaria. Estos resultados tienen grandes implicaciones para la enseñanza-aprendizaje del pensamiento crítico en la educación superior.
\end{abstract}

Palabras clave: educación superior, competencia profesional, pensamiento, aprendizaje, docencia.

\begin{abstract}
Since the development of competency-based learning, there has been a great interest in critical thinking in higher education. Furthermore, enterprises have seen this competence as essential for professional development in an innovative environment. Several authors have studied its concepts and processes as a key element in education and in training. This article is a study about how university teachers understand critical thinking as well as the importance given to this competence. The research, both quantitative and qualitative with 230 teachers involved, shows interesting results, as the majority of teachers link this competence to processes of analysis and reasoning and some to questioning, evaluation, and decision making, but very few understand it as action and commitment. Nevertheless, all of these aspects are very important aspects of university education. Moreover, these results have far-reaching implications for the teaching-learning of critical thinking in higher education.
\end{abstract}

Keywords: higher education, professional competence, thinking, learning, teaching 


\section{INTRODUCCIÓN Y CONTEXTO}

Hay distintas formas de pensamiento: analítico, sistémico, reflexivo, lógico, creativo, analógico, divergente, lateral, convergente, interrogativo, deliberativo, discursivo, colegiado, práctico, deductivo, inductivo, crítico (Villa y Poblete 2007). Todas estas formas de pensar tienen en común que son pensamiento y, a veces, es complicado y difícil distinguirlas. Cada una de ellas tiene algunas características propias, distintivas e incluso procesos y productos diferentes. Quien comprende cuáles son las mejores maneras de pensar y por qué son mejores puede, si lo desea, modificar su propia manera de pensar para mejorar su eficacia, es decir, para realizar mejor el trabajo (Dewey 1989), así como tener un rol más comprometido en la sociedad y vivir de forma más plena.

El pensamiento crítico es una de las formas más mencionadas y presentes en la literatura. Los juicios a los que se llega mediante el pensamiento crítico se basan en criterios que pueden ser primordiales tales como la libertad, la autonomía, la soberanía y la verdad entre otros. El pensamiento crítico implica estar sensibilizados así como contrastar una realidad social, política, ética y personal. En cierto modo, es un compromiso con el "otro", con la sociedad, al tomar una postura de acción transformadora de la persona y de la sociedad (Lipman 1987). De forma holística, es uno de los elementos claves en la consecución de una sociedad sostenible (Wals \& Jickling 2002). La clave no está en tener la razón, sino en tener en cuenta todas las posibilidades y confiar en la razón más que en la emoción, para no permitir que nuestros prejuicios sesguen nuestras decisiones (Kurland 2005). Especialmente en nuestra sociedad en la que los medios sociales parecen dictar nuestra forma de pensar y actuar. El pensamiento crítico es esencial para la innovación, la mejora, la creatividad y el compromiso. De aquí la importancia de desarrollarlo en la escuela y en la universidad.

En todos los ámbitos se tiene en cuenta y se valora el pensamiento crítico. Si nos centramos en un ámbito utilitario como puede ser el universo de todo tipo de organizaciones (desde empresas, hasta ONG, pasando por centros sanitarios, educativos, religiosos, profesionales, sociales, etc.), los empleadores consideran que el pensamiento crítico es uno de los principales requisitos de un empleado, a cualquier nivel que se considere (directivo, técnico, mando intermedio, empleado administrativo u operarios, etc.) dando por sentado que todos los integrantes de la organización desempeñan roles de una responsabilidad, que hacen que el conjunto trabaje con una mayor eficacia. Así aparece comprobado en un informe sobre las competencias que consideran esenciales los empleadores a la hora de contratar colaboradores, siendo al mismo tiempo, según ellos, la competencia más difícil de encontrar (Committee for Economic Development 2015).

En el ámbito laboral, el pensamiento crítico, no sólo es una competencia considerada esencial, como se muestra mediante la coordenada horizontal de la Figura 1, que indica la importancia con que se solicita cada competencia, sino que es difícil encontrarla en los individuos, como refleja la coordenada vertical. Esta competencia, como se observa en el gráfico, se sitúa muy próxima a la resolución de problemas que se presentan en una actividad profesional. Puede aventurarse que son dos tipos de competencia, no sólo próximos, sino que se exigen e implican mutuamente.

El futuro del mundo profesional está fuertemente influido por las Tecnologías de la Información y la Comunicación (TIC) y está siendo necesario redefinir los puestos de trabajo que exigirán la cuarta revolución industrial en que estamos inmersos. Un informe del World Economic Forum predice que esa cuarta revolución industrial, especialmente 
Figura 1. Las competencias esenciales y difíciles de encontrar en el mundo laboral

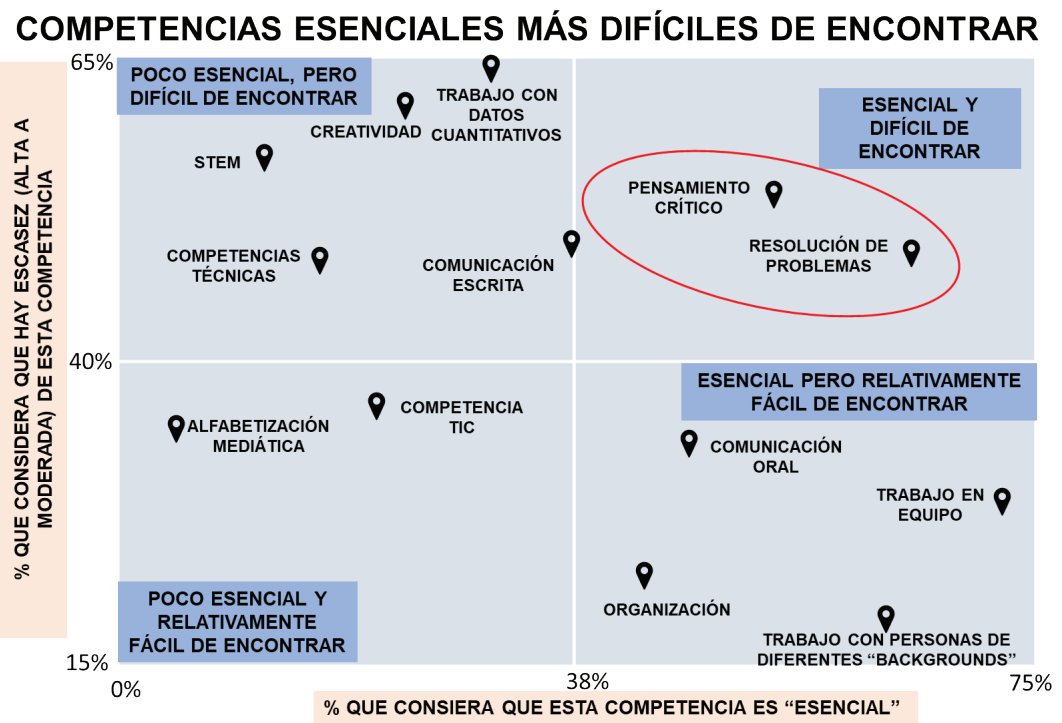

Fuente: Adaptado de Committee for Economic Development, 2015

notable desde diversos ámbitos: la robótica, la inteligencia artificial, la biotecnología, la autonomía en el transporte, la exploración y las actuaciones sobre el genoma, supone un cambio en las prioridades de las competencias exigidas en el curriculum profesional (World Economic Forum 2016). Dicho informe considera que el pensamiento crítico es un proceso básico y aporta la siguiente tabla (tabla 1) que resume los principales cambios en las competencias prioritarias del año 2015 al año 2020.

Tabla 1. Las competencias esenciales para empleadores en los años 2015 y 2020

\begin{tabular}{|c|c|}
\hline 2020 & 2015 \\
\hline 1. Resolución de problemas complejos & 1. Resolución de problemas complejos \\
\hline 2. Pensamiento crítico & 2. Trabajo en equipo \\
\hline 3. Creatividad & 3. Liderazgo \\
\hline 4. Liderazgo & 4. Pensamiento crítico \\
\hline 5. Trabajo en equipo & 5. Negociación \\
\hline 6. Inteligencia emocional & 6. Control de calidad \\
\hline 7. Toma de decisiones & 7. Orientación \\
\hline 8. Orientación & 8. Toma de decisiones \\
\hline 9. Negociación & 9. Aprendizaje activo \\
\hline 10. Pensamiento flexible & 10. Creatividad \\
\hline
\end{tabular}


Este Informe va en línea con lo que diagnosticaba el Comité para el Desarrollo Económico (Committee for Economic Development 2015), que consideraba procesos competenciales básicos y en alza la resolución de problemas y el pensamiento crítico.

El pensamiento crítico no es algo nuevo, sino que ya se considera fundamental en la filosofía antigua. Es el pensamiento de los interrogantes: ¿por qué las cosas son así?, ¿por qué las cosas no pueden ser de otro modo?, ¿por qué alguien puede querer que las cosas sean así? Es la estructura básica del método mayéutica de Sócrates. Se presenta al principio de los sistemas filosóficos que va construyendo la humanidad para interpretar lo que va más allá de lo visible (metafísica). Según Sócrates por una parte, no se trata tanto de aprender por aprender y acumular saberes, sino de poner críticamente en tela de juicio lo que se sabe e ir construyendo la verdad (Sócrates 430-399, a.C.). Por otra parte, plantea que se ha de hacer uso del pensamiento crítico desde el punto de vista del autoconocimiento personal, al tener a la vez un valor social, puesto que su interlocutor es el otro (Paul \& Elder 2007).

En el presente estudio se hace un análisis cualitativo y cuantitativo del concepto e importancia del pensamiento crítico desde la perspectiva de los docentes universitarios. Se parte de la revisión del concepto de pensamiento crítico de diversos autores tales como Ennis (Ennis 1991, 2011, 2007); Paul \& Elder (Paul \& Elder 2003); Villarini (Villarini 2003) y Facione (Facione 2007) para analizar la importancia de este pensamiento en el marco de la educación superior, tanto para el futuro profesional de los estudiantes, como para su formación humana y social.

\section{CONCEPTO DE PENSAMIENTO CRÍTICO}

A pesar de existir coincidencia entre los autores que investigan y escriben sobre el pensamiento crítico, se registra una gran variedad de definiciones, según enfaticen un aspecto u otro o según el ámbito en que se especialicen. Las descripciones facilitan poco la definición de pensamiento crítico como una entidad concreta, ya que cada autor hace de la definición un uso adecuado a su ámbito (filosófico, psicológico, educativo) y aplicación. Una de las definiciones más genéricas fue la elaborada por Robert Sternberg, quien escribía que el pensamiento crítico son los procesos, estrategias y representaciones que la gente utiliza para resolver problemas, tomar decisiones y aprender nuevos conceptos (Robert Sternberg 1986).

En el marco de la educación, Ennis comienza en los años sesenta a estudiar el pensamiento crítico. Para Ennis, es un proceso cognitivo complejo que implica disposiciones y capacidades con tres dimensiones básicas: la lógica (juzgar, relacionar palabras con enunciados), la criterial (utilización de opiniones para juzgar enunciados) y la pragmática (comprensión del juicio y la decisión para construir y transformar el entorno). Se centra en lo que la persona puede decidir, creer o hacer algo de forma reflexiva, razonable y evaluativa. Asimismo, implica un análisis, buscar la verdad a través de criterios y evidencias así como llegar a un juicio de valores. Este proceso se evidencia en situaciones problemáticas en las que hay que adoptar una posición y llevar a cabo una actuación. Asimismo, describe quince capacidades para el pensamiento crítico, siendo las tres últimas habilidades auxiliares (Ennis 1991, 2011, 2016): centrarse en la pregunta; analizar los argumentos; formular preguntas de clarificación y dar una respuesta; juzgar la credibilidad de una fuente; observar y juzgar los informes derivados de la observación; 
deducir y juzgar las deducciones; inducir y juzgar las inducciones; emitir juicios de valor; definir los términos y juzgar las definiciones; identificar los supuestos; decidir la acción que a seguir e interactuar con los demás; integrar disposiciones y otras habilidades para realizar y defender una decisión; proceder de manera ordenada de acuerdo con cada situación; ser sensible a los sentimientos, nivel de conocimiento y grado de sofisticación de los otros; emplear estrategias retóricas apropiadas en la discusión y presentación, tanto oral como escrita (López Aymes 2013). Ennis clasifica estas capacidades en tres grupos: la clarificación, la base de una decisión, la inferencia, y añade dos habilidades metacognitivas, la suposición y la integración (Ennis 2001).

Por otro lado, Bloom evoca seis aspectos del pensamiento crítico, de creciente complejidad e íntimamente ligados al proceso de aprendizaje (Bloom 1971). La taxonomía va desde el orden inferior al superior: desde recoger información hasta juzgar un resultado (Anderson \& Krathwohl 2001). Los niveles que propone son:
1. Conocimiento
2. Comprensión
3. Aplicación
4. Análisis
5. Síntesis
6. Evaluación

Este modelo, que Bloom plantea para explicar la progresividad del aprendizaje viene a ser un proceso de pensamiento crítico que profundiza en el conocimiento y puede aplicarse a otros ámbitos que no sean el educativo.

Scriven \& Paul piensan que se puede formar y guiar al estudiante para conceptualizar, aplicar, analizar, sintetizar y evaluar información a través de la experiencia y de la reflexión, así como llegar a una opinión y a una manera de actuar consciente. Según su visión, el pensamiento crítico tiene dos componentes: por una parte, un conjunto de destrezas de producción y procesamiento de información y creencias y, por otra, el hábito de utilizar dichas destrezas para guiar su comportamiento (Scriven \& Paul 2003).

Siguiendo en el mundo de la enseñanza, el pensamiento crítico supone la habilidad para explorar un problema, cuestión o situación; integrar la información válida sobre los mismos, llegar a una solución o hipótesis y justificar una propuesta (Warnick \& Inch 1994; citado en Petress 2004: 461). Para Petress el pensamiento crítico incluye la evaluación del proceso que lleve a la toma de decisiones, por lo que requiere "tiempo, energía, habilidad y dedicación" (Petress 2004: 463). Añade este autor que es necesario integrar en la definición del pensamiento crítico los siguientes criterios: suficiencia, relevancia, fiabilidad, consistencia, actualidad, accesibilidad, objetividad. En el proceso formativo, recoge las siguientes características de un pensador crítico (Ferrett 1997; citado en Petress 2004: 463): plantear las oportunas cuestiones; evaluar argumentos; admitir vacíos de conocimientos o información; tener curiosidad; estar interesado en hallar nuevas soluciones; definir con claridad criterios para analizar ideas; examinar creencias, convencimientos y opiniones y contrastarlos con los hechos; escuchar cuidadosamente a los otros y ser capaz de dar "feedback"; suspender el juicio antes de haber recogido y considerado todos los hechos; acreditar asunciones y creencias en base a evidencias; revisar opiniones ante nuevos hechos; buscar beneficios; examinar problemas cuidadosamente; rechazar información incorrecta 
o irrelevante; considerar que el pensamiento crítico es un proceso vital de autoafirmación. Estas características, según Petress, están imbuidas de un sentido dialógico, que a su vez da sentido al valor social del pensamiento crítico (Petress 2004).

Paul \& Elder, definen el pensamiento crítico como un modo de pensar en el cual "el pensante mejora la calidad de su pensamiento al apoderarse de las estructuras inherentes del acto de pensar y al someterlas a estándares intelectuales". El resultado es un pensador crítico que formula preguntas con claridad y precisión, que evalúa información, que llega a conclusiones y soluciones a base de criterios relevantes, que piensa con una mente abierta y da soluciones a problemas complejos. Añaden estos autores que el pensamiento crítico es "auto-dirigido, auto-disciplinado, autorregulado, y auto-corregido" (Paul \& Elder (2003: 4).

Para Villarini el sistema del pensamiento se articula en tres subsistemas dependiendo de factores de adaptación e histórico-culturales: sistema de representación o codificación que forma significado (imágenes, nociones, conceptos); sistema de operaciones o la forma de organizar o reorganizar la información y sistema de actitudes (emociones, sentimientos, valores). Para Villarini, el pensamiento crítico se define como "la capacidad del pensamiento para examinarse y evaluarse a sí mismo (el pensamiento propio o el de los otros)" (Villarini 2003: 39). Este examen y evaluación tienen como resultado una mejora en la persona y en su entorno. Es relevante en Villarini la vinculación de la educación del pensamiento crítico en la actividad política y social. Según este autor es un proceso que lleva a la implicación, al compromiso y a la solidaridad, después de un proceso individual. Para que el aprendizaje sea auténtico, incluido el del pensamiento crítico, las actividades en clase tienen que ser significativas, activas, reflexivas, colaborativas y empoderadoras (Villarini 2003).

Para Facione, los buenos pensadores críticos se definen función de lo que hacen, cómo lo hacen y cómo llegan a una síntesis. Facione concluye que el pensamiento crítico es "el proceso del juicio intencional, auto regulado" (Facione 2007: 22). Para este proceso Facione propone seis pasos (Facione 2007: 17):

1. Identificar el problema

2. Definir el contexto

3. Enumerar las opciones

4. Analizar las razones explícitamente

5. Listar las razones explícitamente

6. Autorregulación

El pensamiento crítico, añade este autor, impregna toda la vida y le da sentido; va más allá del aula. Es una competencia esencial en la investigación, en la educación, así como en la vida personal y cívica de cada uno.

Desde el punto de vista del docente, Moore, después de una entrevista con 17 académicos de tres áreas de conocimiento (historia, filosofía y estudios culturales y literarios) para conocer su visión y conceptualización del pensamiento crítico, distingue las siguientes siete categorías en el concepto del pensamiento crítico: emitir juicios; tener una visión escéptica y cuestionadora de la realidad; ser original y producir conocimiento; leer de forma sensata y cuidadosa un texto; racionalidad y forma de razonamiento; adoptar una postura ética y activista; y como autorreflexión y autoconciencia (Moore 2013). Esta aportación supone un análisis y categorización de la visión del pensamiento crítico de los docentes universitarios en la práctica, uno de los objetivos del presente estudio. Moore 
es consciente de que su estudio es limitado, aun así demuestra la variedad de respuestas que dan los docentes para definir la competencia, al tratarse de un término polisémico. Su aportación también remarca la convicción y el compromiso de los docentes de incluir en sus aulas dicha competencia.

En síntesis, podría decirse que lo característico del pensamiento crítico es que se trata de un pensamiento orientado a la comprensión y resolución de problemas, a la evaluación de alternativas y a la toma de decisiones. El pensamiento crítico implica comprender, evaluar y resolver. Implica autoevaluación, pensar acerca del pensamiento (metapensamiento) y estar seguro de no pasar, sin fundamento suficiente, a conclusiones. En la educación superior, el pensamiento crítico es uno de los elementos claves en la consecución de una sociedad sostenible. Por dicho motivo, hay que educar en la crítica, en una nueva forma de pensar, de evaluar y de hacer. La universidad da la oportunidad de confrontar valores, prácticas, pedagogías, programas de aprendizaje, etc. con la comunidad y que dicho aprendizaje se vea reflejado en la vida profesional del estudiante de forma sostenible (Wals \& Jickling 2002). El pensamiento crítico puede llegar a una actuación y a un compromiso propio y social. Por eso su importancia, no sólo en la educación, sino en el mundo profesional.

\section{PENSAMIENTO CRÍTICO Y FORMACIÓN UNIVERSITARIA}

Educar en pensamiento crítico es educar para la vida al tener como fin una acción transformadora en la etapa educativa, profesional y en la vida personal. La enseñanzaaprendizaje de la competencia genérica de pensamiento crítico en el aula es un debate abierto, no sólo en el mundo universitario, sino también en la educación tanto primaria como secundaria. La razón principal es que es una competencia de transferencia para actuar y comprometerse en la sociedad, cuyo impacto se puede ver a largo plazo y fuera de las aulas. En cuanto a la función del pensamiento crítico en la vida universitaria hay distintas opiniones en el ámbito académico. La razón es simple, ya que en la adquisición de esta competencia influyen otros factores contextuales. Autores, como Arum \& Roksa, han estudiado el impacto del pensamiento crítico y han llegado a la conclusión de que es imposible enseñarlo a nivel universitario, debido a que nadie sabe lo que implica esta competencia ni en qué consiste (Arum \& Roksa 2011b). Para estos autores, los estudiantes universitarios en los primeros años no tienen las herramientas para hacer tareas que impliquen, entre otras competencias, el pensamiento crítico (Arum \& Roksa 2011a). Sin embargo, Pascarella, Blaich, Martin \& Hanson analizan el estudio de Arum \& Roksa (Arum \& Roksa 2011a) y piensan que no se puede concluir tan tajantemente que no tenga un valor añadido en la universidad (Pascarella, Blaich, Martin \& Hanson 2011).

Hay un punto de vista intermedio, como el de Altuve entre otros autores, que es de la opinión que el pensamiento crítico depende del área de estudio o de investigación (Altuve 2010). Thompson considera que el pensamiento crítico se puede enseñar tanto a nivel universitario como a nivel escolar, pero existe una falta de claridad por parte de los docentes, puesto que muchas veces no entienden bien el concepto (Thompson 2011). A pesar de que hay unanimidad al considerar que es una competencia esencial para el estudiante, a los docentes no les resulta fácil ni explicarla ni enseñarla. El pensamiento crítico es una habilidad parcialmente adquirida, que necesita de docentes adecuados que puedan equipar al estudiante con las estrategias adecuadas para desenvolverse en el 
siglo XXI (Asgharheidari \& Tahiri 2015; Abrami et al. 2015; Abrami et al. 2008). Huber \& Kuncel opinan que es difícil saber hasta qué punto la universidad o la madurez del estudiante es lo que influye en la adquisición de las competencias. Dicen que es posible que la competencia del pensamiento crítico incremente con la edad, con las experiencias vividas y no sólo con la educación universitaria (Huber \& Kuncel 2016). No se cuestionan que una competencia, como el pensamiento crítico, es de hecho, transferible a la vida personal y social del estudiante y no depende únicamente de un proceso de aprendizaje en el aula.

Un ejemplo es el estudio de Pessoa \& Urzêda Freitas, los cuales prueban que se puede impartir el pensamiento crítico en asignaturas como lengua y que es una forma de motivar al estudiante en el proceso dialógico, ya que ayuda a considerar el lenguaje como una práctica social en la cual se involucra al estudiante para que esté sensibilizado ante la injusticia social (Pessoa \& Urzêda Freitas 2012). Este hecho puede adecuarse a cualquier asignatura e implica al estudiante y al docente por igual adoptando una enseñanza-aprendizaje crítico.

Otros autores dan pautas para su inclusión en la educación universitaria. Halpern propone un modelo para guiar la enseñanza y el aprendizaje del pensamiento crítico a través del trabajo cognitivo y de la enseñanza en las habilidades del pensamiento crítico (Halpern 1998). Otros autores, como Thompson, consideran que es más efectiva la educación que incorpora formas de crear nuevos productos o hipótesis a partir de información existente y significativa para el estudiante. Según esta autora, el pensamiento crítico debería ser transversal a toda la enseñanza universitaria y no a una sola asignatura, curso o facultad (Thompson 2011). Por otro lado, otros autores, como Abrami et al. dudan de si el pensamiento crítico es transversal a varias asignaturas o áreas o si se puede aplicar solamente en una asignatura o contexto (Abrami et al. 2008).

Es significativo que muchos docentes reconocen la importancia de enseñar el pensamiento crítico. Sin embargo, pocos lo incorporan a sus asignaturas (Asgharheidari \& Tahiri 2015). Un estudio realizado en Estados Unidos, citado por Butler (Butler 2012), indica que el ochenta y uno por ciento de empleadores requieren que se instruya mejor a los estudiantes para incorporarse al mundo laboral. Es decir, que a pesar de ser considerada una competencia clave en la educación de los estudiantes universitarios, (Abrami et al. 2008), no está muy incorporada en las asignaturas en la universidad. El pensamiento crítico puede y debe ser enseñado no sólo en la universidad sino en la educación secundaria. Abrami et al. concluyen que el pensamiento crítico puede ser enseñado a cualquier nivel y destacan el diálogo significativo y la resolución de problemas como las metodologías más apropiadas para su desarrollo (Abrami et al. 2015). A pesar de no obviar que es la madurez del estudiante lo que realmente influye en la aplicación de esta competencia en su vida social y personal.

\section{OBJETIVO DEL PRESENTE TRABAJO}

Con esta investigación se pretende hacer una incursión en la enseñanza-aprendizaje del pensamiento crítico en el ámbito de la enseñanza superior. El desarrollo del pensamiento crítico está condicionado por múltiples factores, entre otros, las características de cada estudiante, lo que el docente entiende por pensamiento crítico y la manera que lo aplica en la asignatura que imparte. De la concepción e importancia que los profesores dan al 
pensamiento crítico, depende, en buena forma, el aprendizaje de los estudiantes. Por tanto, este estudio tiene como objetivo el análisis de diferentes aspectos:

1. ¿En qué grado consideran importante los docentes universitarios el desarrollo del pensamiento crítico en sus estudiantes y hasta qué punto lo trabajan en sus asignaturas?

2. ¿Qué idea tienen los docentes universitarios sobre la competencia de pensamiento crítico y cómo la definen?

3. ¿Depende esta concepción del área de conocimiento a la que pertenece la asignatura que imparten? ¿Y de los años de experiencia docente?

4. ¿Existen diferencias significativas entre el profesorado de Latinoamérica y el profesorado de España con respecto a las cuestiones anteriormente mencionadas?

\section{METODOLOGÍA}

En el estudio se aplica una metodología mixta, cualitativa/cuantitativa, ya que, a partir de un cuestionario con preguntas abiertas y cerradas, algunos datos se analizan cuantitativamente y otros de manera cualitativa empleando el juicio ciego de cuatro jueces, que trabajan conjuntamente en el análisis de contenido.

\subsection{MUESTRA}

La muestra del estudio está formada por 230 docentes universitarios, de diferentes áreas de conocimiento, provenientes de universidades públicas y privadas de España y América Latina (ver Tabla 2) con los que previamente los integrantes del equipo de investigación habían establecido algún tipo de colaboración en trabajos de innovación y formación docente. De los 326 docentes de la muestra invitada, 230 respondieron a la solicitud de participación, un 70,55 \% de la muestra invitada. De éstos, 82 eran españoles y 148 de países latinoamericanos, principalmente de Chile y Ecuador, el resto de países están poco representados (8,4\% en total). El $33 \%$ pertenecían a universidad pública y el 67 $\%$ a universidad privada. La mayoría imparte docencia en el área de Ciencias Sociales y Jurídicas (36\%), seguido de Artes y Humanidades (23\%), Ingeniería y Arquitectura (19\%), Ciencias de la Salud (13\%) y Ciencias (9\%). El $54 \%$ eran mujeres y el $46 \%$ hombres.

Casi un $90 \%$ (88\%) de los docentes de la muestra tienen entre 31 y 60 años, siendo los porcentajes de profesorado entre los distintos tramos de edad definidos muy similares: $30-40$ años (30\%), 41-50 años (27\%) y 51-60 años (31\%). Tan solo un 4\% tiene menos de 30 años y un $8 \%$ más de 60 . La mayor parte de los docentes tiene gran experiencia docente, casi un $80 \%$ tiene entre 11 y 30 años de experiencia. Tan solo un 9\% tienen menos de 5 años de experiencia docente. 
Tabla 2. Distribución de la muestra

\begin{tabular}{|c|c|c|c|}
\hline & & $\mathrm{N}$ & $\%$ \\
\hline \multirow[t]{9}{*}{ País } & Argentina & 5 & 2,2 \\
\hline & Bolivia & 5 & 2,2 \\
\hline & Chile & 70 & 30,4 \\
\hline & Ecuador & 40 & 17,4 \\
\hline & España & 82 & 35,7 \\
\hline & Guatemala & 5 & 2,2 \\
\hline & República Dominicana & 7 & 3,0 \\
\hline & Uruguay & 12 & 5,2 \\
\hline & Otros (México, Colombia, Costa Rica, Venezuela) & 4 & 1,7 \\
\hline \multirow[t]{2}{*}{ Tipo de universidad } & Pública & 76 & 32,8 \\
\hline & Privada & 154 & 66,4 \\
\hline \multirow[t]{5}{*}{ Área de conocimiento } & Artes y Humanidades & 54 & 23,3 \\
\hline & Ciencias & 22 & 9,5 \\
\hline & Ciencias de la Salud & 29 & 12,5 \\
\hline & Ciencias Sociales y Jurídicas & 82 & 35,3 \\
\hline & Ingeniería y Arquitectura & 43 & 18,5 \\
\hline \multirow[t]{2}{*}{ Género } & Mujeres & 124 & 53,4 \\
\hline & Hombres & 106 & 45,7 \\
\hline \multirow[t]{5}{*}{ Edad } & $<30$ & 9 & 3,9 \\
\hline & $30-40$ & 69 & 29,7 \\
\hline & $41-50$ & 63 & 27,2 \\
\hline & $51-60$ & 71 & 30,6 \\
\hline & $>60$ & 18 & 7,8 \\
\hline \multirow[t]{5}{*}{ Experiencia docente } & $<5$ años & 21 & 9,1 \\
\hline & $5-10$ & 54 & 23,3 \\
\hline & $11-20$ & 73 & 31,5 \\
\hline & 21-30 & 47 & 20,3 \\
\hline & $>30$ & 35 & 15,1 \\
\hline
\end{tabular}

Estos datos nos permitirán analizar los resultados en función de las distintas variables contempladas. 


\subsection{INSTRUMENTO DE RECOGIDA DE DATOS}

Para dar respuesta a los objetivos de investigación, se diseñó un cuestionario, que consta de dos apartados, uno con datos descriptivos de la muestra, y otro con preguntas abiertas y cerradas con relación al pensamiento crítico y su aplicación en la docencia. Se trata de un cuestionario breve y en formato online para facilitar la respuesta de los docentes.

En concreto, el cuestionario se componía de algunos ítems que han sido tratados de manera cuantitativa para conocer las dimensiones concretas de la muestra y su alcance:

- Datos de contexto

- Tipo de universidad y país de origen.

- Área (Titulación o Departamento).

- Género, Edad, Experiencia.

- Importancia y posibilidad de aplicación del pensamiento crítico

Además, se han incluido tres cuestiones abiertas, centrándose este artículo en el análisis cualitativo de la primera de ellas:

- Qué considera cada docente que es el pensamiento crítico y cómo lo define.

- Qué metodologías emplean para su desarrollo en los estudiantes.

- Cuál/es de ellas funciona/n mejor.

\subsection{PROCEDIMIENTO PARA LA RECOGIDA DE DATOS}

Como ya se ha señalado, los invitados a participar en el estudio fueron 326 docentes de universidades públicas y privadas, de España y diferentes países de América Latina, que previamente habían mantenido algún tipo de colaboración con los integrantes del equipo de investigación. A partir del diseño de la base de datos de contactos, el cuestionario se envió desde el sistema de mensajería interna del programa Qualtrics el 28 de septiembre de 2016. Un mensaje de agradecimiento y recordatorio fue enviado el 14 de octubre. Las respuestas fueron recogidas y procesadas con el programa Qualtrics, manteniendo el anonimato de los participantes.

\section{RESULTADOS}

Se presenta el análisis de los resultados obtenidos tras la aplicación y respuesta a la primera parte del cuestionario: que concepto de Pensamiento crítico tienen los docentes.

\subsection{IMPORTANCIA Y APLICABILIDAD DEL PENSAMIENTO CRÍTICO}

El estudio pone de manifiesto el interés que entre el profesorado suscita el tema propuesto ya que un $70,55 \%$ de respuestas recibidas válidas puede considerarse como excelente, teniendo en cuenta además que la recogida de datos ha sido online. Además, evidencia que la forma de elegir y cuidar la muestra ha sido muy eficaz. 
A continuación se presentan los resultados correspondientes a las preguntas cuantitativas del estudio que hacían referencia a la importancia y enseñanza del pensamiento crítico entre los docentes universitarios (Figura 2), añadiendo algunos ejemplos que ilustran los datos obtenidos.

Figura 2. Importancia y posibilidad de aplicación del pensamiento crítico en la Enseñanza Superior

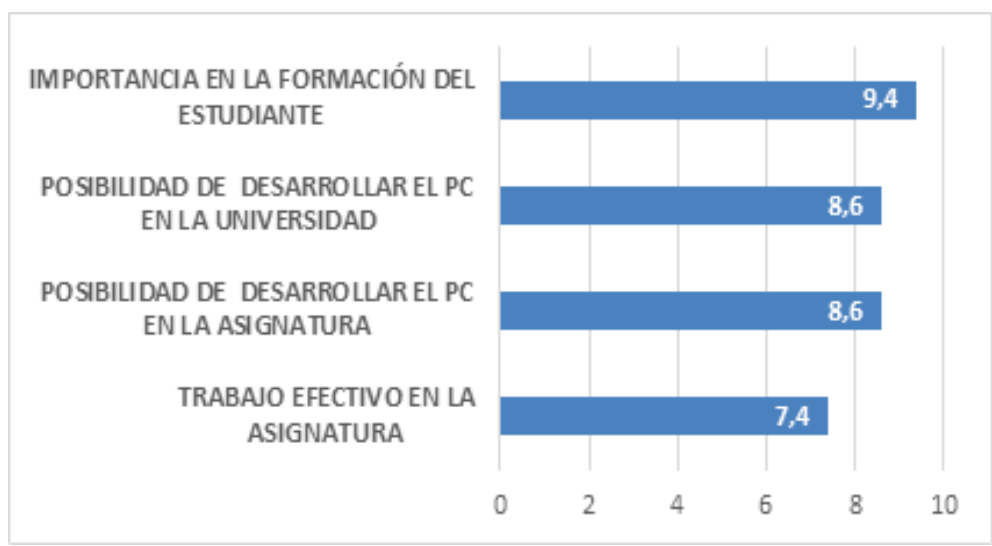

El profesorado considera muy importante la enseñanza del pensamiento crítico en la educación superior (media de 9,4), no habiendo ninguno que le otorgue una puntuación inferior a 5 y el $66 \%$ de la muestra le da una puntuación de 10. Ejemplos de respuesta a esta pregunta son:

"Es de vital importancia el desarrollo del pensamiento crítico de tal suerte que representa un capital humano determinante a la hora de formular y gestionar iniciativas de consenso, articuladas y de equipo en orden a objetivos y metas complejas" (S.230).

"Es indispensable para que la persona pueda desarrollar su potencial y aportar a la sociedad lo mejor de sí mismo" (S.228).

"Debería ser de máxima prioridad. Sin pensamiento crítico no hay autonomía de pensamiento" (S.223).

"Es uno de los pilares de una universidad humanista" (S.204).

"La clave del pensamiento que debe desarrollar la universidad es justamente el pensamiento crítico, una comprensión reflexiva de la realidad poniendo realce a los prejuicios acerca de ella y entregando otras posibilidades de comprensión de la misma. Esto en vista de un pensamiento transformador de la realidad" (S.116). 
La mayoría de ellos considera que es posible trabajarlo en la universidad (8,6 sobre 10$)$ y en sus asignaturas $(8,6)$. Expresiones típicas de esta forma de respuesta son:

"Sí es posible, pero los modelos de enseñanza-aprendizaje, basados en el modelo de competencias, aplicados en la educación dificultan ese proceso" (S.219).

"Debería poderse... pero se necesitan mejores condiciones: principalmente el trabajar en clase con grupos reducidos" (S.218).

"Cuesta mucho. La orientación es aún muy enfocada a la memorización y no al pensamiento" (S.209).

"No totalmente, porque va a depender de la formación del académico, además de su interés en trabajar en torno a estimular el pensamiento crítico en los estudiantes" (S.208).

"Por supuesto. A través de las dinámicas de conversación que se dan en el aula y en espacios más individuales (tutorías, seguimiento, proyectos...). Desde el rol de profesor tutor debería ser una de las competencias a fomentar de manera transversal" (S.55).

Hay que resaltar que son menos los docentes que consideran que realmente están trabajando el pensamiento crítico en sus asignaturas (7,4 sobre 10), siendo un $5 \%$ los docentes que lo trabajan muy poco, $23 \%$ lo trabajan algo, $49 \%$ lo trabajan bastante y tan solo un $23 \%$ lo trabajan mucho. Expresiones características de estas respuestas son:

"Considero que colaboro a un nivel de ocho porque es una asignatura de primero y se emplea mucho tiempo en explicar contenidos. He puntuado ocho por la dinámica de problematizar críticamente procesos de argumentación" (S.101).

"Lo intento siempre" (S.146).

"Los tiempos y resultados a corto plazo siempre apremian" (S.173).

"Considero que el pensamiento crítico siempre está presente, aunque se ha de compaginar con alguna otra competencia específica" (S.118).

"El curriculum y los contenidos me impiden hacerlo con mayor profundidad" (S.106).

Aplicada la t de student a las medias arrojadas por el colectivo de docentes de Latinoamérica y de España, la diferencia entre ambos no es significativa. Podríamos hablar de una sola muestra homogénea en cuanto a posibilidad de aplicar el pensamiento crítico en la propia asignatura (Tabla 3). 
Tabla 3. Importancia y aplicabilidad en España y en Latinoamérica.

\begin{tabular}{|l|c|c|}
\hline & España & Latinoamérica \\
\hline ¿En qué grado considera importante desarrollarlo en los estudiantes? & 9,28 & 9,52 \\
\hline En su opinión, ¿es posible desarrollarlo en la universidad? & 8,80 & 8,50 \\
\hline En concreto ¿es posible desarrollarlo en su asignatura? & 8,49 & 8,42 \\
\hline $\begin{array}{l}\text { ¿En qué medida considera usted que trabaja el Pensamiento Crítico } \\
\text { en su asignatura? }\end{array}$ & 7,41 & 7,39 \\
\hline
\end{tabular}

Ante la pregunta de si el pensamiento crítico está contemplado explícitamente como una competencia asignada a su asignatura, se observa que esto es así en un 47,83\% de los casos. Aunque no se plantee su desarrollo de manera explícita, realmente se trabaja y los docentes apuestan por formar personas críticas. El no haberla incluido explícitamente no equivale necesariamente a que no hayan trabajado el pensamiento crítico. Existe la posibilidad de que sean conscientes de que implícitamente la trabajan, a través de las metodologías y actividades que utilizan en su asignatura.

\subsection{CONCEPCIÓN DE PENSAMIENTO CRÍTICO: ANÁLISIS DE DEFINICIONES}

El profesorado consultado responde a la pregunta "¿Qué es para usted el pensamiento crítico?" con diversas definiciones que pueden agruparse de distintas maneras. Pocos docentes dan una definición simple (solamente reflexionar o evaluar o analizar, por ejemplo). La mayoría define el pensamiento crítico como un proceso complejo con diversidad de elementos implicados, por lo que en la definición tienen en cuenta analizar para decidir o razonar para actuar o preguntarse para discriminar. El equipo investigador ha realizado un agrupamiento de las definiciones dadas por los docentes en las siguientes seis categorías: analizar, razonar, cuestionar, evaluar, tomar decisiones y actuar. Las categorías se han definido siguiendo un proceso inductivo, atendiendo a la complejidad de los procesos implicados en las definiciones dadas por los docentes. Así por ejemplo, se considera la evaluación más compleja que el análisis y el compromiso más complejo que el razonamiento. Estas seis categorías han sido confirmadas por un análisis correlacional realizado con los resultados de toda la muestra. Aún sabiendo que todos los procesos están relacionados, es importante crear estas categorías para comprender qué entiende el profesorado por pensamiento crítico, y por tanto, qué tipo de estudiante se está formando y qué metodologías pueden ser las más adecuadas dependiendo de las concepciones subyacentes.

Para llegar a estas categorías se analizó cada una de las definiciones dadas por los docentes, intentando ver qué procesos de pensamiento subyacían a cada una de ellas. En este proceso de análisis de contenido, nos dimos cuenta de que en una misma definición podían darse procesos distintos (analizar, evaluar, etc.) y con el fin de no perder información se registraron todos ellos. De allí que en el total aparezcan más respuestas que sujetos.

La codificación de las categorías se realizó atendiendo a los siguientes criterios: 
Analizar/Organizar: Son respuestas que hacen referencia al pensamiento crítico como manera de examinar detalladamente algo (un texto, una realidad ...) considerando sus partes para conocer sus características y extraer conclusiones. En algunos casos, incluyen aspectos relacionados con la estructuración y organización de la información, pero no van más allá de ello.

Razonar/Argumentar: Estas definiciones añaden al análisis la relación y comparación de ideas y experiencias en base a argumentos, para obtener conclusiones y formar un juicio razonado. Implica expresar de palabra o por escrito razones a favor o en contra de algo, o justificarlo como una acción razonable para transmitir un contenido y fomentar el entendimiento.

Cuestionar/Preguntarse: El pensamiento crítico es entendido como el cuestionamiento o puesta en duda de un asunto que resulta controvertido o que es comúnmente aceptado, armando para ello una serie de preguntas. Significa cuestionarse las cosas, hacerse preguntas sobre la realidad en que uno vive.

Evaluar: Significa valorar, ponderar, determinar el valor de algo, estimar la importancia de un hecho, teniendo en cuenta diversos elementos o criterios. Es más que una argumentación (deducir pros y contras de una realidad) porque implica determinar el valor de algo en función de unos criterios.

Posicionarse/Tomar decisiones: Como su nombre indica, implica no sólo analizar, razonar, cuestionar o evaluar, sino tomar una decisión al respecto. Significa dar una solución o emitir un juicio definitivo sobre un asunto de una determinada manera, incluye un posicionamiento o propuesta de solución.

Actuar/Comprometerse: Es un nivel superior, en el que el pensamiento crítico es entendido como un medio de transformación de la realidad desde el compromiso social. Es pasar a la acción, obrar, comportarse realizando actos voluntarios y conscientes de una manera determinada y comprometida. Implica la adopción de una determinada actitud o posición ante un determinado asunto.

Se recogen a continuación las frecuencias y porcentajes de la codificación de las definiciones de los docentes (Tabla 4).

Tabla 4. Respuestas según categorías.

\begin{tabular}{|ll|c|}
\hline \multirow{2}{*}{ Categorías } & \multicolumn{2}{|c|}{ Respuestas } \\
\cline { 2 - 3 } & Definiciones & $\%$ \\
\hline 1. Analizar/Organizar & 130 & 26,9 \\
\hline 2. $\quad$ Razonar/Argumentar & 123 & 25,4 \\
\hline 3. Cuestionar/Preguntarse & 54 & 11,2 \\
\hline 4. $\quad$ Evaluar & 72 & 14,9 \\
\hline 5. Posicionarse/Tomar decisiones & 88 & 18,2 \\
\hline 6. Actuar/Comprometerse & 17 & 3,5 \\
\hline Total & 484 & 100 \\
\hline
\end{tabular}


A continuación, se presentan algunos ejemplos de cómo definen el pensamiento crítico los docentes, en función de las categorías encontradas (Tabla 5).

Tabla 5. Evidencias de categorías de pensamiento crítico

\begin{tabular}{|c|c|}
\hline Categorías & Extractos textuales \\
\hline Analizar/Organizar & $\begin{array}{l}\text { "es la capacidad de analizar la información entregada, procesarla, } \\
\text { jerarquizarla y entregar una opinión respecto a una situación o tema" } \\
\text { (S.196) } \\
\text { "es la capacidad de analizar, sopesar, comparar toda la información que se } \\
\text { tiene para dar respuesta a una situación que puede ser nueva o antigua" } \\
\text { (S.222) } \\
\text { "es un proceso que permite organizar las ideas y conocimiento con la } \\
\text { finalidad de llegar a respuestas objetivas" (S.7) } \\
\text { "es una manera de abordar los temas tanto científicos como no científicos. } \\
\text { Es una habilidad de analizar, organizar y plantear nuevos retos a partir de } \\
\text { la documentación analizada" (S.33) }\end{array}$ \\
\hline Razonar/Argumentar & $\begin{array}{l}\text { "es la capacidad de razonar un argumento o hipótesis, analizando y } \\
\text { distinguiendo qué parte puede ser siempre cierta, qué parte puede depender } \\
\text { de las condiciones de contorno y qué parte puede depender del estado } \\
\text { personal" (S.145) } \\
\text { "es la capacidad de razonar, reflexionar y construir argumentos propios } \\
\text { frente a diversos contenidos o aspectos teóricos determinados" (S.27) } \\
\text { "es realizar juicios argumentados, discriminando la calidad de la } \\
\text { información, exponiendo correcta y ordenadamente y pensar de manera } \\
\text { autónoma" (S.165) } \\
\text { "es una forma de pensamiento basada en el pensamiento científico en la } \\
\text { que el individuo sabe argumentar su posición respecto a algún tópico bajo } \\
\text { análisis" (S.200) }\end{array}$ \\
\hline Cuestionar/Preguntarse & $\begin{array}{l}\text { "cuestionarse las cosas, los resultados, no dar nada por hecho" (S.17) } \\
\text { "el que nos lleva a cuestionar opiniones y comportamientos propios y } \\
\text { ajenos y pensar en las consecuencias de los actos, el que nos dota de } \\
\text { criterios fundamentados y nos ayuda a ser coherentes" (S.32) } \\
\text { "preguntarse por el sentido de las cosas, por qué son así y si podrían ser de } \\
\text { otra manera" (S.101) } \\
\text { "es un proceso mental mediante el que se procesan los porqués, los pros y } \\
\text { contras de las situaciones habituales y excepcionales para encontrarles } \\
\text { una explicación y, en ocasiones, una solución coherente y práctica" } \\
\text { (S.189) }\end{array}$ \\
\hline Evaluar & $\begin{array}{l}\text { "es la capacidad de evaluar de forma objetiva los problemas" (S.189) } \\
\text { "evaluar con argumentos y criterios valiosos previamente establecidos" } \\
\text { (S.151) } \\
\text { "es la capacidad de evaluar una situación con elementos aparentemente } \\
\text { desconectados y aplicarlos a la situación o problema" (S.201) } \\
\text { "es evaluar permanentemente la información recibida, complementarla y } \\
\text { tener los argumentos necesarios para discutir los aspectos que no están } \\
\text { claros" (S.223) }\end{array}$ \\
\hline
\end{tabular}




\begin{tabular}{|c|c|}
\hline $\begin{array}{l}\text { Posicionarse/Tomar } \\
\text { decisiones }\end{array}$ & $\begin{array}{l}\text { "poder tomar decisiones razonadas en base a un conocimiento objetivo" } \\
\text { (S.177) } \\
\text { "la capacidad de razonar y aplicar la lógica y el raciocinio a la decisión a } \\
\text { tomar" (S.112) } \\
\text { "análisis constructivo de la realidad, basado en las interacciones entre } \\
\text { conceptos, con el objeto de tomar decisiones para la solución de } \\
\text { problemas"(S.158) } \\
\text { "capacidad para determinar la credibilidad de la información que recibe y } \\
\text { su análisis para tomar decisiones y normar sus criterios en función de la } \\
\text { misma" (S.56) }\end{array}$ \\
\hline Actuar/Comprometerse & $\begin{array}{l}\text { "la capacidad de analizar una realidad atendiendo a los supuestos de su } \\
\text { comprensión tradicional y atendiendo a ella con nuevos supuestos, en } \\
\text { vistas a realizar un pensamiento transformador de la realidad" (S.117) } \\
\text { "analizar y valorar el conocimiento que adquirimos, contrastándolo con el } \\
\text { que poseemos, lo que derivará en una reconstrucción de nuestro } \\
\text { pensamiento y modo de leer, afrontar, entender, interactuar, etc. el mundo } \\
\text { que nos rodea" (S.123) } \\
\text { "es la capacidad de análisis que presenta un sujeto al momento de } \\
\text { presentarse frente a una situación, la cual le permite guiar su actuar en } \\
\text { dicho momento; y también, le permite analizar diversos agentes que } \\
\text { pueden involucrarse en el desarrollo de una acción o actividad" (S.195) } \\
\text { "es un ejercicio de carácter cognitivo que permite realizar juicios y tomar } \\
\text { decisiones en una realidad compleja que sistemáticamente presenta } \\
\text { nuevas formas de diálogo y acción social" (S.51) }\end{array}$ \\
\hline
\end{tabular}

En resumen, la mayor parte de docentes define el pensamiento crítico como "Analizar/ Organizar" y "Razonar/Argumentar" $(52,3 \%)$ y son pocos $(3,5 \%)$ los que llegan a incluir en la definición el "Actuar/Comprometerse". Es decir, pocos docentes conciben el pensamiento crítico con la connotación de acción e implicación social.

Otra cuestión que ha llamado la atención es el lenguaje empleado por los docentes a la hora de definir el pensamiento crítico y de entenderlo como capacidad o proceso, como habilidad o actitud o, incluso, como acción. Así, por ejemplo:

"Pensamiento crítico es la capacidad para comprender y formular asertiva y ponderadamente factores asociados en el planteamiento de objetos de comprensión y determinar sus dinámicas tanto sincrónicas como diacrónicas" (S.231).

"Pensamiento crítico es un proceso cognitivo que, fundamentado en la información, la observación y la experiencia le permite al individuo analizar y reflexionar la realidad para cuestionarla y comprenderla con objetividad" (S.230).

"Pensamiento crítico es realizar juicios y emitir opiniones en base a un análisis de diferentes fuentes de información, considerando diversos puntos de vista y evidencias documentadas a fin de pensar o bien en algunos casos tomar decisiones en forma autónoma" (S.6). 
"Pensamiento crítico es una actitud por la que no aceptamos directamente los juicios y opiniones de los demás, si no antes de someterlos a nuestro propio raciocinio y experimentación" (S.15).

"Pensamiento crítico es una habilidad propia del ser humano que debe ser cultivada a lo largo de toda la vida" (S.167).

Como se observa en la Tabla 6, la mayor parte de docentes define el pensamiento crítico como capacidad en primer lugar y como proceso en segunda instancia. A cierta distancia, lo consideran más como acción y como actitud y muy pocos lo entienden como habilidad. Las definiciones del pensamiento crítico como actitud y habilidad se aproximan más a la de pensamiento como capacidad y las definiciones como acción tienen relación con las de proceso. Esto pone de manifiesto que no hay un uso riguroso del lenguaje y que el profesorado, utilizando diversos términos, puede estar refiriéndose a lo mismo. En todo caso, a través del análisis del lenguaje, se podrían distinguir dos concepciones de pensamiento crítico, una referida al pensamiento crítico como algo más estático, inherente a la persona (capacidad, actitud, habilidad) y otra más referida al pensamiento crítico como proceso de desarrollo vinculado a la acción.

Tabla 6. Clasificación de las definiciones según el lenguaje utilizado

\begin{tabular}{|l|c|c|}
\hline & Definiciones & $\%$ \\
\hline Capacidad & 116 & 50 \\
\hline Proceso & 69 & 30 \\
\hline Acción & 23 & 10 \\
\hline Actitud & 18 & 8 \\
\hline Habilidad & 4 & 2 \\
\hline Total & 230 & 100 \\
\hline
\end{tabular}

En este momento en el que el concepto de competencia está siendo muy relevante en la educación superior quizá convendría ser riguroso en la utilización de estos términos, que en sí mismos responden a conceptos muy diferentes, aunque no siempre son tratados así en la literatura. Por ejemplo, el término inglés de "skill" se refiere en algunos casos a nuestro concepto de competencia, si bien algunos autores trabajan ya con el término "competency" o "competence".

\subsection{CONCEPCIÓN DE PENSAMIENTO CRÍTICO EN FUNCIÓN DE DIFERENTES VARIABLES}

Se ha analizado si existen diferencias en la concepción del pensamiento crítico según las siguientes variables: origen, tipo de universidad, área de conocimiento, género, edad y experiencia docente. 
En función de la procedencia, según los docentes trabajen en universidades españolas o latinoamericanas, no se observan grandes diferencias, excepto en que más docentes españoles entienden el pensamiento crítico como "cuestionamiento" y más docentes de Latinoamérica lo entienden como "evaluación” (Tabla 7).

Tabla 7. Agrupación de las definiciones por origen de las universidades de los profesores.

\begin{tabular}{|l|c|c|c|c|}
\hline \multirow{2}{*}{ Categorías } & \multicolumn{2}{|c|}{ Latinoamérica } & \multicolumn{2}{c|}{ España } \\
\cline { 2 - 5 } & $\mathrm{N}$ & $\%$ & $\mathrm{~N}$ & $\%$ \\
\hline Analizar/ Organizar & 88 & $28,1 \%$ & 42 & $24,6 \%$ \\
\hline Razonar/ Argumentar & 80 & $25,6 \%$ & 43 & $25,1 \%$ \\
\hline Cuestionar/ Preguntarse & 25 & $8,0 \%$ & 29 & $17,0 \%$ \\
\hline Evaluar & 52 & $16,6 \%$ & 20 & $11,7 \%$ \\
\hline Posicionarse/ Tomar decisiones & 56 & $17,9 \%$ & 32 & $18,7 \%$ \\
\hline Actuar/ Comprometerse & 12 & $3,8 \%$ & 5 & $2,9 \%$ \\
\hline Total & 313 & $100 \%$ & 171 & $100 \%$ \\
\hline
\end{tabular}

Con respecto a las diferentes concepciones de pensamiento crítico en funciòn de universidad pública o privada, se observan algunas diferencias en cuanto a la concepción del pensamiento crítico como "evaluación", más presente en las universidades privadas, y la concepción de pensamiento crítico como "toma de decisiones" y "actuar/ comprometerse", más presente en las universidades públicas (Tabla 8).

Tabla 8. Tipo de universidad

\begin{tabular}{|l|c|c|c|c|}
\hline \multirow{2}{*}{ Categorías } & \multicolumn{2}{|c|}{ Pública } & \multicolumn{2}{c|}{ Privada } \\
\cline { 2 - 5 } & $\mathrm{N}$ & $\%$ & $\mathrm{~N}$ & $\%$ \\
\hline Analizar/Organizar & 41 & $25,0 \%$ & 89 & $27,8 \%$ \\
\hline Razonar/Argumentar & 42 & $25,6 \%$ & 81 & $25,3 \%$ \\
\hline Cuestionar/Preguntarse & 21 & $12,8 \%$ & 33 & $10,3 \%$ \\
\hline Evaluar & 15 & $9,1 \%$ & 57 & $17,8 \%$ \\
\hline Posicionarse/tomar decisiones & 37 & $22,6 \%$ & 51 & $15,9 \%$ \\
\hline Actuar/Comprometerse & 8 & $4,9 \%$ & 9 & $2,8 \%$ \\
\hline Total & 164 & $100 \%$ & 320 & $100 \%$ \\
\hline
\end{tabular}


Los análisis por área de conocimiento indican que en general, predominan las definiciones que hacen referencia a "Analizar/Organizar" y "Razonar/Argumentar". Los docentes de Ciencias de la Salud son los que más variedad de definiciones registran, seguidos de los docentes de Ciencias Sociales y Jurídicas. Los docentes de Ciencias son los que menos consideran el pensamiento crítico como "evaluación" (Tabla 9).

Tabla 9. Agrupación por área disciplinar

\begin{tabular}{|l|c|c|c|c|c|c|c|c|c|c|}
\hline \multirow{2}{*}{ Categorías } & \multicolumn{2}{|c|}{$\begin{array}{c}\text { Artes y } \\
\text { Humanidades }\end{array}$} & \multicolumn{2}{|c|}{ Ciencias } & \multicolumn{2}{c|}{$\begin{array}{c}\text { Ciencias } \\
\text { de la Salud }\end{array}$} & \multicolumn{2}{c|}{$\begin{array}{c}\text { Ciencias Sociales } \\
\text { y Jurídicas }\end{array}$} & \multicolumn{2}{|c|}{$\begin{array}{c}\text { Ingeniería y } \\
\text { Arquitectura }\end{array}$} \\
\cline { 2 - 13 } & $\mathrm{N}$ & $\%$ & $\mathrm{~N}$ & $\%$ & $\mathrm{~N}$ & $\%$ & $\mathrm{~N}$ & $\%$ & $\mathrm{~N}$ & $\%$ \\
\hline $\begin{array}{l}\text { Analizar/ } \\
\text { Organizar }\end{array}$ & 29 & $26,1 \%$ & 13 & $33,3 \%$ & 19 & $31,1 \%$ & 50 & $26,9 \%$ & 19 & $21,8 \%$ \\
\hline $\begin{array}{l}\text { Razonar/ } \\
\text { Argumentar }\end{array}$ & 29 & $26,1 \%$ & 13 & $33,3 \%$ & 12 & $19,7 \%$ & 48 & $25,8 \%$ & 21 & $24,1 \%$ \\
\hline $\begin{array}{l}\text { Cuestionar/ } \\
\text { Preguntarse }\end{array}$ & 11 & $9,9 \%$ & 3 & $7,7 \%$ & 4 & $6,6 \%$ & 25 & $13,4 \%$ & 11 & $12,6 \%$ \\
\hline $\begin{array}{l}\text { Evaluar } \\
\text { Posicionarse/ } \\
\text { Tomar } \\
\text { decisiones }\end{array}$ & 20 & $18,0 \%$ & 2 & $5,1 \%$ & 11 & $18,0 \%$ & 26 & $14,0 \%$ & 13 & $14,9 \%$ \\
\hline $\begin{array}{l}\text { Actuar/ } \\
\text { Comprometerse }\end{array}$ & 4 & $3,6 \%$ & 3 & $7,7 \%$ & 3 & $4,9 \%$ & 4 & $2,2 \%$ & 3 & $3,4 \%$ \\
\hline Total & 111 & $100 \%$ & 39 & $100 \%$ & 61 & $100 \%$ & 186 & $100 \%$ & 87 & $100 \%$ \\
\hline
\end{tabular}

Con respecto a los años de experiencia docente, los resultados indican que a mayor experiencia docente, mayor comprensión del pensamiento crítico como "cuestionamiento"; se observa una progresión en este sentido. Llama la atención que los docentes con menos de 5 años de experiencia entienden el pensamiento crítico fundamentalmente como "posicionamiento/toma de decisiones" y no como "analizar/organizar" o "razonar/ argumentar" modalidad en que lo hacen el resto de grupos superiores en años de experiencia (Tabla 10). 
Tabla 10. Años de experiencia docente

\begin{tabular}{|c|c|c|c|c|c|c|c|c|c|c|}
\hline \multirow{2}{*}{ Categorías } & \multicolumn{2}{|c|}{$\begin{array}{c}\text { Menos } \\
\text { de } 5 \text { años }\end{array}$} & \multicolumn{2}{|c|}{$\begin{array}{c}\text { Entre } \\
5 \text { y } 10 \text { años }\end{array}$} & \multicolumn{2}{|c|}{$\begin{array}{l}\text { Entre } \\
11 \text { y } 20\end{array}$} & \multicolumn{2}{|c|}{$\begin{array}{l}\text { Entre } \\
21 \text { y } 30\end{array}$} & \multicolumn{2}{|c|}{$\begin{array}{l}\text { Más } \\
\text { de } 31 \text { años }\end{array}$} \\
\hline & $\mathrm{N}$ & $\%$ & $\mathrm{~N}$ & $\%$ & $\mathrm{~N}$ & $\%$ & $\mathrm{~N}$ & $\%$ & $\mathrm{~N}$ & $\%$ \\
\hline $\begin{array}{l}\text { Analizar/ } \\
\text { Organizar }\end{array}$ & 10 & $23,3 \%$ & 31 & $27,7 \%$ & 40 & $26,7 \%$ & 26 & $26,3 \%$ & 23 & $28,8 \%$ \\
\hline $\begin{array}{l}\text { Razonar/ } \\
\text { Argumentar }\end{array}$ & 10 & $23,3 \%$ & 29 & $25,9 \%$ & 41 & $27,3 \%$ & 25 & $25,3 \%$ & 18 & $22,5 \%$ \\
\hline $\begin{array}{l}\text { Cuestionar/ } \\
\text { Preguntarse }\end{array}$ & 3 & $7,0 \%$ & 11 & $9,8 \%$ & 15 & $10,0 \%$ & 13 & $13,1 \%$ & 12 & $15,0 \%$ \\
\hline Evaluar & 6 & $14,0 \%$ & 20 & $17,9 \%$ & 24 & $16,0 \%$ & 14 & $14,1 \%$ & 8 & $10,0 \%$ \\
\hline $\begin{array}{l}\text { Posicionarse/ } \\
\text { Tomar } \\
\text { decisiones }\end{array}$ & 12 & $27,9 \%$ & 18 & $16,1 \%$ & 24 & $16,0 \%$ & 19 & $19,2 \%$ & 15 & $18,8 \%$ \\
\hline $\begin{array}{l}\text { Actuar/ } \\
\text { Comprometerse }\end{array}$ & 2 & $4,7 \%$ & 3 & $2,7 \%$ & 6 & $4,0 \%$ & 2 & $2,0 \%$ & 4 & $5,0 \%$ \\
\hline Total & 43 & $100 \%$ & 112 & $100 \%$ & 150 & $100 \%$ & 99 & $100 \%$ & 80 & $100 \%$ \\
\hline
\end{tabular}

El análisis de las variables género y edad no aporta diferencias reseñables, en cuanto a la categorización de las definiciones de pensamiento crítico.

\section{DISCUSIÓN}

Este estudio demuestra la importancia del pensamiento crítico en la formación universitaria, así como en la formación integral del individuo. Evidencia que el pensamiento crítico es un concepto complejo y que es entendido de diferentes maneras por los docentes (Thompson 2011). Tras el análisis de las definiciones se han podido determinar unas categorías que incluyen las diferentes concepciones de pensamiento crítico que tiene el profesorado y que pueden ayudar al docente a comprobar si se está aplicando esta competencia en toda su complejidad.

La investigación evidencia que el pensamiento crítico es considerado esencial entre los docentes universitarios, tanto españoles como latinoamericanos. Sin embargo, no se trabaja en igual medida en las asignaturas y los docentes manifiestan ciertas dificultades para trabajarlo en el aula. Queda evidenciado que el pensamiento crítico se sitúa preferentemente en los niveles de "analizar/organizar" y "razonar/argumentar". El estudio asimismo manifiesta que el profesorado no ve el pensamiento crítico tanto como "cuestionar/preguntarse", "evaluar" o "posicionarse/tomar decisiones" y aún menos como "actuar/comprometerse". Por otro lado, no parece haber muchas diferencias en función del 
país de origen, área de conocimiento, tipo de universidad (privada o pública), género, edad y experiencia docente.

Las categorías que se han deducido del análisis de las respuestas de los docentes coinciden con el concepto de pensamiento crítico de algunos autores que llevan tiempo estudiando esta competencia. Así, Ennis (Ennis 1991, 2011, 2016), entre otros, habla del pensamiento crítico como análisis, entre otros procesos, al hablar de la habilidad que denomina clarificación, ya que, como observa, hay que conocer la situación para poder reaccionar, proponer o juzgar. Asimismo, al igual que Facione, afirma que el pensamiento crítico implica razonamiento y argumentación (Facione 2007). Paul \& Elder enfatizan la idea de pensamiento crítico como cuestionamiento e inciden en que la calidad de las preguntas que nos formulamos nos preparan para reconocer lo esencial en la vida, tanto a nivel personal, social, educativo como profesional (Paul \& Elder 2003). También consideran, junto con Facione, los procesos de evaluación y autoevaluación, más complejos si se entienden como un juicio de valor que lleva a la toma de decisiones (Facione 2007). Para Villarini el fin de la competencia de pensamiento crítico está en la construcción de un mundo significativo para conseguir una liberación política y social refiriéndose, en concreto, al mundo latino (Villarini 2003). Asimismo, Moore, en su análisis sobre el concepto de pensamiento crítico según los docentes, menciona el compromiso social y la acción crítica (Moore 2013).

Es muy importante que en la universidad exista univocidad en cuanto a la definición de pensamiento crítico, sobre todo si se considera competencia clave o sello de la universidad. Los docentes deberían interiorizar y aplicar la visión adoptada por la universidad puesto que no es lo mismo formar a estudiantes desde una perspectiva de pensamiento crítico como "Analizar/Organizar" que como de "Decidir/Tomar decisiones" o como compromiso y acción social.

Una conclusión importante del presente estudio es la aportación de un modelo de organización del pensamiento crítico, concebido como un proceso en el que pueden diferenciarse varios niveles de desarrollo y que necesariamente va a requerir de diferentes estrategias de enseñanza-aprendizaje para su desarrollo, adaptadas al grado de madurez en los estudiantes (Figura 3). Este modelo ayudaría al docente a ver, de manera sistémica, el concepto de pensamiento crítico en toda su dimensión y a moverse de un nivel a otro con una estrategia coherente dentro de un mismo proceso.

En función de la progresividad existente entre las categorías de definiciones dadas por los docentes, se proponen tres niveles de dominio y dificultad. En primera instancia, puede hablarse de un nivel de "análisis/organización" y "razonamiento/argumentación", consistente en conocer los datos de la situación o problema y reflexionar sobre los mismos, como elementos integrantes de la realidad. Para ello será necesario observar con detenimiento, entrar en procesos de información y de obtención y manejo de datos. Un nivel de mayor intensidad es el del cuestionamiento y evaluación de la situación o problema. Ligando con la etapa anterior habrá que analizar en elementos simples los datos que se encuentran o presentan a primera vista. Será necesario cuestionar y prescindir de certezas, poniendo en tela de juicio las mismas, haciendo una valoración y atribución de importancia a los elementos presentados. Se utilizarán procesos de inducción y/o deducción, contrastando la visión propia con otras visiones, que contribuyan a tener una mejor comprensión de la realidad. En tercer lugar, una vez que se hayan aclarado las dudas, lo anterior llevará a posicionarse, a tomar decisiones y a actuar en la resolución del 
problema planteado o la mejora de una situación. La persona puede hacerse responsable y comprometerse mediante las acciones que se deriven de su posicionamiento.

Figura 3. Modelo de pensamiento crítico

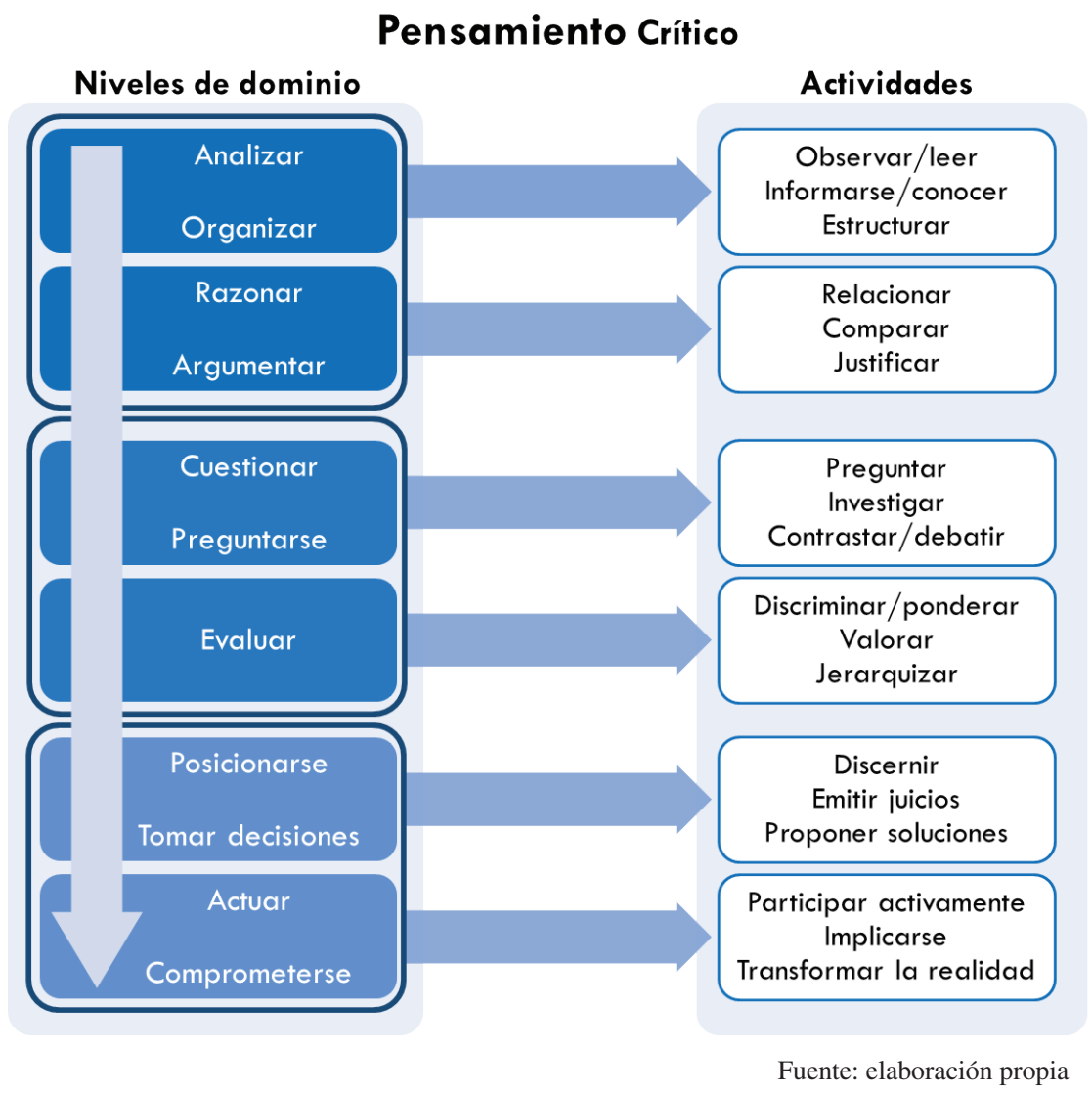

Este modelo sugiere que pueden organizarse actividades que supongan el nivel de complejidad descrito y cabe deducir que el desarrollo del pensamiento crítico en el estudiante implica seguir un recorrido que puede emplear los años que dure su formación universitaria. Dado que se trata de una competencia que no termina en el aula, sino que es transferible a toda la vida del estudiante y se adquiere en todos los aspectos que influyen en la madurez de la persona, se puede trabajar en la universidad a través de otro tipo de actividades como deporte, cultura, solidaridad, etc. Lo que es indudable es que es una competencia clave en la educación, para la formación integral del individuo y que está en alza en el mundo universitario y profesional.

Tras este trabajo de investigación, quedan muchos interrogantes, así como futuras líneas de estudio. En concreto, algunas de ellas son: 
- ¿Cuál es la forma más eficaz de trabajar el pensamiento crítico? ¿Se puede sustraer de la materia o asignatura en que trabaja cada profesor, existiendo (o debiendo existir) una especie de competencia transversal válida para todas?

- ¿Qué metodologías son las más adecuadas para trabajar el pensamiento crítico en el aula?

- ¿Cómo introducir estas metodologías en el aula? ¿Adaptando las metodologías utilizadas en función de la competencia de pensamiento crítico? ¿Incorporando otras nuevas?

- ¿Cómo evaluar la competencia pensamiento crítico tanto en la fase inicial del proceso, como en las intermedias y final? ¿Cómo evaluar y medir su progresión y desarrollo?

Por tanto, investigaciones que aborden los planteamientos metodológicos y de evaluación del pensamiento crítico serían pertinentes y relevantes para la mejora de la docencia universitaria.

\section{REFERENCIAS BIBLIOGRÁFICAS}

Abrami, P., Bernard, R.M., Borokhovski, A., Wade, A., Surkes, M.A., Tamin, R., \& Zhang, D. (2008). Instructional interventions affecting critical thinking skills and dispositions: A stage 1 metaanalysis. Review of Educational Research, 78(4), 1102-1134.

Abrami, P., Bernard, R., Borokhovski, E., Waddington, D.I., Wade, C.A., \& Persson, T. (2015). Strategies for teaching students to think critically: A meta-analysis. Review of Educational Research, 85(2), 275-314.

Alexander, B., Adams Becker, S., Cumminns, M., \& Hall Glesinger, C. (2017). Digital Literacy in Higher Education, Part II: An NMC Horizon Project Strategic Brief. Vol. 3.4, August 2017. Austin, Texas: The New Media Consortium. Recuperado el 20 de marzo de 2017 desde https:// cdn.nmc.org/media/2017-nmc-strategic-brief-digital-literacy-in-higher-education-II.pdf

Altuve, J. G. (2010). El pensamiento crítico y su inserción en la educación superior. Actualidad Contable Faces, 13(20), 5-18.

Anderson, L. W.,\& Krathwohl, D. R. (Eds.) (2001) A Taxonomy for Learning, Teaching, and Assessing: A Revision of Bloom's Taxonomy of Educational Objectives. Boston, MA: Allyn \& Bacon.

Arum, R., \& Roksa, J. (2011a). Limited learning on college campuses. Springer Science \& Business Media, 48, 203-207. doi: 10.1007/s12115-011-9417-8

Arum, R., \& Roska, J. (2011b). Academically adrift: Limited learning on college campuses. Chicago: Chicago University Press.

Asgharheidari, F., \& Tahiri, A. (2015). A survey of EFL teachers' attitudes towards critical thinking instruction. Journal of Language Teaching and Research, 6(2), 388-396.

Bloom, B. S. (1971). Taxonomía de los objetivos de la educación: Clasificación de las metas educacionales: manuales I y II. Buenos Aires: El Ateneo.

Butler, H. (2012). Halpern critical thinking assessment predicts real-world outcomes of critical thinking. Applied Cognitive Psychology, 26, 721-729.

Committee for Economic Development (2015). What are the essential competencies on the job? Recuperado el 16 de julio de 2017 desde https://www.insidehighered.com/sites/default/server_ files/files/151007\%20CED\%20Survey\%20Results\%203.pdf

Dewey. J. (1989). Cómo pensamos. Paidós: Barcelona. 
Ennis, R.H. (1991). Critical Thinking: A streamlined conception. Teaching Philosophy, 14 (1), 5-24.

Ennis, R.H. (2001). Critical Thinking assessment. Theory into Practice, 2 (2), 179-186.

Ennis, R.H. (2011). The Nature of Critical Thinking: An Outline of Critical Thinking Dispositions and Abilities. Recuperado el 20 de mayo de 2017 desde http://faculty.education.illinois.edu/ rhennis/documents/TheNatureofCriticalThinking_51711_000.pdf

Ennis, R. H. (2016). Critical Thinking Across the Curriculum: A Vision. Topoi, 1-20. doi: 10.1007/ s11245-016-9401-4

Facione, P. A. (2007). Pensamiento Crítico: ¿Qué es y por qué es importante? Recuperado el 17 de mayo de 2017 desde http://eduteka.icesi.edu.co/pdfdir/PensamientoCriticoFacione.pdf

Halpern, D. (1998). Teaching critical thinking for transfer across domains: Dispositions, skills, structure training, and metacognitive monitoring. American Psychologist, 53(4), 449-455.

Huber, C.R. \& Kuncel, N.R. (2016). Does College Teach Critical Thinking? A Meta-Analysis. Review of Educational Research, 86 (2), 431-468.

Kurland, D. (2005). Lectura crítica versus pensamiento crítico. Recuperado el 16 de julio de 2017 desde http://www.bvs.sld.cu/revistas/mciego/alfin_2012/alfin_folder/2012\%20Unidad\%205/ Bibliograf\%EDas/Lect\%20B\%E1sicas/Lectura_basica_7._Lectura_critica_versus_ pensamiento_critico.pdf

Lipman, M. (1987). Critical Thinking: What can it be? Analytic Teaching, 8(1), 5-12.

López Aymes, G. (2013). Pensamiento crítico en el aula. Docencia e Investigación, 22, 41-60.

Moore, T. (2013). Critical thinking: Seven definitions in search of a concept. Studies in Higher Education, 38(4), 506-522.

Pascarella, E.T, Blaich, C., Martin, G.L. \& Hanson, J.M. (2011). How robust are the findings of "Academically Adrift". Change: The Magazine of Higher Learning, 43(3), 20-24.

Paul, R. \& Elder, L. (2003). La mini-guía para el pensamiento crítico. Conceptos y herramientas. Recuperado el 16 de julio de 2017 desde https://www.criticalthinking.org/resources/PDF/SPConceptsandTools.pdf

Paul, R. \& Elder, L. (2007). The Thinker's Guide to The art of Socratic Questioning. Foundation for Critical Thinking. Recuperado el 16 de julio de 2017 desde https://www.criticalthinking.org/ store/get_file.php?inventories_id=231\&inventories_files_id=374

Pessoa, R., \& Urzêda Freitas, M.D. (2012). Challenges in Critical language teaching. Tesol quarterly, 46(4), 753-776.

Petress, K. (2004). Critical thinking: An extended definition. Education, 124(3), 461-466.

Scriven, M. \& Paul, R. (2003). Defining critical thinking. Recuperado el 20 de marzo de 2017 desde http://www.criticalthinking.org/pages/defining-critical-thinking/766

Sternberg, R. J. (1986). Critical Thinking: Its Nature, Measurement and Improvement. Washington DC: National Institute of Education.

Thompson, C. (2011). Critical thinking across the curriculum: Process over output. International Journal of Humanities and Social Science, 1(9), 1-7.

Villa, A. y Poblete, M. (2007). Aprendizaje Basado en Competencias. Una propuesta para la evaluación de las competencias genéricas. Bilbao: Ediciones Mensajero.

Villarini, A. R. (2003). Teoría y pedagogía del Pensamiento Crítico. Perspectivas Psicológicas, 3-4, $35-42$.

Wals, A.E.J., \& Jickling, B. (2002). "Sustainability" in higher education. From doublethink and newspeak to critical thinking and meaningful learning. International Journal of Sustainability in Higher Education, 3(3), 221-232. doi: 10.1108/14676370210434688

World Economic Forum (2016). The future of jobs: Employment, skills and workforce strategy for the fourth Industrial Revolution. Recuperado el 20 de marzo de 2017 desde http://www3. weforum.org/docs/WEF_Future_of_Jobs.pdf 
